\title{
The Development of Active Personal Protective Equipment Design Technologies
}

\author{
Alexander Pavlovich Tyurin ${ }^{1}$, Andrey Vladimirovich Balagurov ${ }^{1}$, Alexander Mikhaylovich Zikov ${ }^{1}$, Anton \\ Andreevich Shaklein ${ }^{1} \&$ Petr Mikhailovich Zavialov ${ }^{1}$ \\ ${ }^{1}$ Kalashnikov Izhevsk State Technical University, Udmurt Republic, Russia \\ Correspondence: Alexander Pavlovich Tyurin, Kalashnikov Izhevsk State Technical University, Udmurt \\ Republic, Russia. E-mail: asd1978@mail.ru
}

Received: October 26, 2014

doi:10.5539/mas.v9n3p299
Accepted: November 3, $2014 \quad$ Online Published: February 28, 2015

URL: http://dx.doi.org/10.5539/mas.v9n3p299

\begin{abstract}
This research exposes the designing technology of analogue active personal hearing protective equipment. The achievements overview and following stages of the design include substantiation and calculation of quenching wave formation circuit, component selection, scheme performance testing based on computer-aided means, designing of three-dimensional model of headphones based on the technical characteristics and the weight and size. Testing of experimental model of headphones in three different versions of the concept is carried out to evaluate the effectiveness of noise reduction in standardized octave bands. The test result showed that the analogue headphones have the effectiveness of the noise reduction of $32 \mathrm{~dB}$, which is comparable with the digital type of active headphones produced by Peltor Company.
\end{abstract}

Keywords: phase inverter, analogue active headphones, designing, sound attenuation, electrical circuit

\section{Introduction}

Designing of effective personal equipment for hearing protection from the harmful effects of industrial noise is a priority for the preservation of life and health of employees. Such personal protective equipment is designed to protect the hearing of workers engaged in labor activities in the working area of industrial, office, public buildings or in the open areas. Use of these devices makes it possible not to carry out reconstruction of the working areas, they are low in cost and easy to use (Balagurov and Tyurin, 2011; Chong and McPherson, 2013).

However, most modern facilities provide only passive noise reduction function, that is, only suppress the high-frequency signals. At the same time, a major detrimental factor in producing a low-frequency noise generated by for example, air flows in pipes or channels, or determined, for example, by acoustic emission during operation of diesel engines (Elamin et al., 2010). To overcome the low-frequency noise more effective methods are needed. And one of these methods is the active noise cancelation providing noise suppression using the principle of wave interference (Thom et al., 2005). Active headphones using signal processing method allow to reduce the sound pressure levels of permanent and non-permanent source, audible in the work area including impulse noise.

Basically, the means of active noise cancellation process waves through complex algorithms implemented in the microprocessor (Schumacher et al., 2011; Gaikwad et al., 2013; Akhtar et al., 2004). The development of such an algorithm, its implementation and verification is an expensive process, involving high costs. However it allows to solve a number of special problems (Molesworth et al., 2013; Gan and Kuo, 2003). Effective results can be achieved using an analog signal converter (Pawelczyk, 2001), and development of such equipment requires an examination of their effectiveness on special test stands (Instr. Man.: Hearing-Protector Test Fixture Type 45CA, 2014).

The aim of this study is to provide an efficient means of an analog active noise protection. The main stages are development of the analog phase inverter scheme, its verification in computer-aided design systems and construction of the experimental sample of active noise protection device. The result is an active noise protection device, which effectively suppresses harmful industrial noise through the use of the developed approach to design. 


\section{Theoretical Studies}

\subsection{Evaluation of the Existing Analogues}

As a rule, effective personal hearing protection equipment available on the market is a subject to intellectual property rights.Thus, there is an application for an invention "Headset with a microphone device" on Russian patent "Chashechniy naushnik s microfonnim ustroistvom" (RU № 2007144203 A, 2007) which is a headphone system consisting of two cups interconnected by a shackle. The cups consist of two parts: internal, which forms a noise-canceling space and external, where electronic apparatus and the power source are located. The cups are made of plastic. On the inner side of the outer part of the cup cup there is an aperture for a microphone provided with a wind shield, made as a continuation of the external surfaces of the outer side of the cup. The disadvantage of this technical solution is a complicated, specially made cups shape, the presence of separate parts, walls and edges, which complicates the manufacturing process and increases the weight of the product. Another known technical solution is the solution according to patent US № 6965681 "Arrangement in acoustic headsets” (US № 6965681, 2005), which has a microprogram control unit, combined with radio receiver module. The right cup has an analyzing microphone, control buttons, as well as a radio receiver antenna module on the outer side. Inside of the right cup there is a printed circuit board with microprogram control unit that is an active noise cancelation based on digital signal processing is implemented in such a solution. The battery compartment is situated in the outer part of the left cup. Both cups are interconnected by a flexible cable and the shackle.

The disadvantage of this technical solution is its low efficiency of noise isolation associated with the processing of the noise signal only on the physical parameters, without any regard to its physiological effects on humans. Moreover the necessity to program the microprocessor presents some difficulties as well. Another drawback is the presence of special board holders, a large number of technological holes, compartments, slots and hollows for the control buttons, as well as complicated, specially made cup shape. Additionally, there is a difficulty in switching between the modules of the system.

The closest analogue is the device presented in the article "Build these noise-cancelling headphones" (Ryckebusch, 1997). Its main element is the phase inverter circuit, performed on three low-noise operational amplifiers, mounted in a plastic housing, and switched with separately placed headphones and microphones with a help of cables. This device has an analog signal processing circuit. The signal from the microphone is inverted and fed to broadband loudspeakers located in ear cups.

The disadvantages of this device are its bulkiness, composite structure of individual devices, the use of heavy battery, which makes it impossible to integrate the system directly into the headset. Furthermore, a large number of connecting cables and wires used in the device degrades signal quality. A method of processing of an analog signal also does not include the relationship between physical parameters of the noise and its physiological effect.

\subsection{Produced Item's Features}

Due to the foregoing, one of inventive problem of the research is to improve the noise protection, by pre-adjustment (balancing) of the input noise to the temporal and frequency characteristics of auditory equivalent noise for highly variable, impulse and pulsating sound processes. That is, the relationship between the physical parameters of the noise and its physiological effects should be considered. Another object is to reduce the dimensions of the headphones with increased usability. Then the technical result is in converting the signal from the pre-processing it in matching unit, the output from which in its temporal and frequency characteristics of the noise correspond to the susceptibility of human auditory analyzer.

Constructively, the task set is achieved by the active headphones consist of headphones cups provided with loudspeakers and microphones (Figure 1). Additionally there is a processing unit, which consists of series-connected matching units, the input amplifier, phase inverter and the output of the amplifier. The output of the input amplifier is also connected to the input of the output amplifier connected to loudspeakers. The matching unit is arranged to set the operating mode of active headphones depending on the function to be performed: reduction of noise exposure, or use as an auxiliary means of hearing by supplying a signal either to the inverting chip or directly to the output amplifier.

Authors proposed signal processing method of active headphones which include signaling from microphones to loudspeakers. The signal from the microphone is fed to a processing unit in which it is aligned, amplified, and then inverted with following amplification, or just amplified without any inversion. Then processed signal is fed to broadband loudspeakers. In this case, with the concurrence of the signal the choice of mode of headphones is provided depending on the function that should active headphones execute: reduction of noise exposure or use as 
an auxiliary means of hearing. This effect can be achieved by supplying a signal to the inverting chip or directly to the output amplifier. In Figure 2, a block diagram of one of two identical channels of the device is displayed.

According to Figure 1 active headphones are two cups with loudspeakers 1 connected with shackle. The cup consists of a body 2 and the sealing cushion 3. The switch 4 and Volume knob 5 are set in the body of the right cup in specially made apertures with thread. Analyzing microphones 6 are attached in both cups in specially made apertures on the adhesive base or by soldering. The control unit 7 is mounted in the body of the right cup on special racks with screws. The control unit 7 presented in detail in Figure 2, contains a matching unit 7.1, input amplifier 7.2, inverting chip (phase inverter) 7.3 and an output amplifier 7.4. Batteries 8 are mounted in the right cup as well. Active headphones work as follows.

When the headphones are turned on by the button 4 analyzing microphones 6 start operating. When noise sound waves proceed to analyzing microphones 6 signal is supplied to the control unit 7 .

In control unit 7 signal first proceeds to matching unit 7.1. In the matching unit 7.1 the signal is processed, which result in the temporal and frequency characteristics of the noise signal correspond to the characteristics of its susceptibility by human auditory analyzer, that is, the processed signal has auditory equivalence.

The operation mode of active headphones which means amplification or attenuation of the noise signal is also set in the matching unit 7.1. Then the signal comes to the input amplifier 7.2 of the control unit 7. Next depending on the mode of the headphones set in the matching unit 7.1, the signal may go either of two ways: to inverting chip 7.3, or directly to the output amplifier 7.4. In the first case an antiphase output signal is obtained, that is the reduction of noise exposure as the main function of noise canceling headphones is provided.

In the second case, the signal amplification is obtained as a secondary function, and headphones can be used as an auxiliary auditory means.

The signal is then supplied to loudspeakers 1 depending on the headphones operation mode with higher or lower sound output respectively. The signal level can be adjusted by the knob 5 .
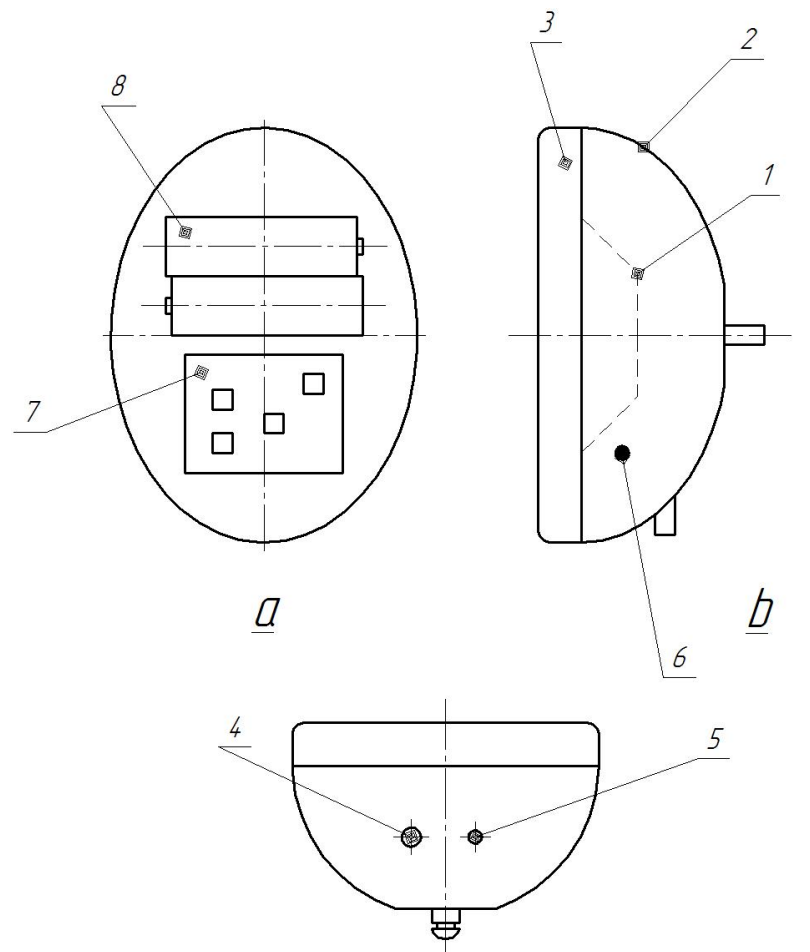

$\underline{\leftarrow}$

Figure 1. Active headphones design

$\mathrm{a}$ - front view, $\mathrm{b}$ - side view, c - top view; 1 - loudspeakers connected with shackle, 2 - body, 3 - sealing cushion, 4 - switch, 5 - volume control, 6 - analyzing microphones, 7 - control unit, 8 - batteries. 


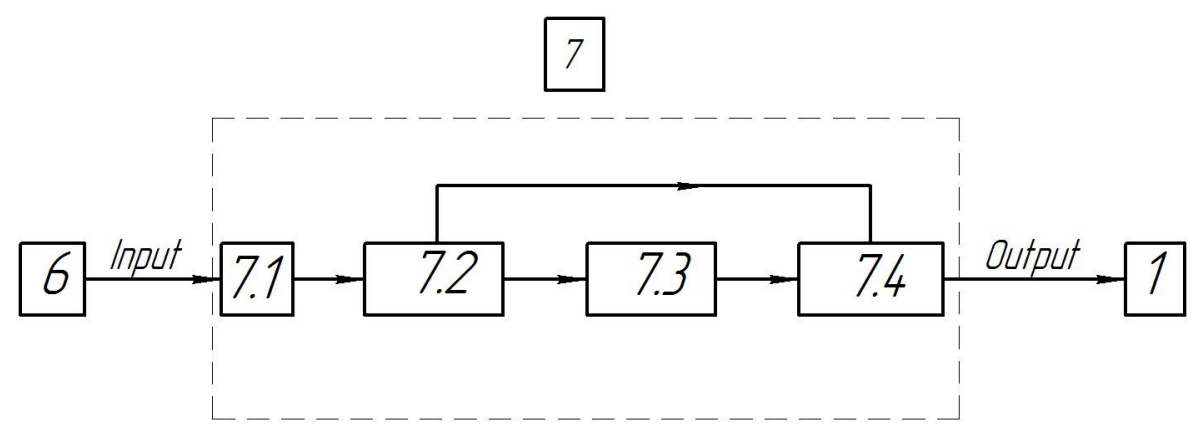

Figure 2. One of two identical device channels block diagram

6 - analyzing microphones; 7 - control unit, consisting of: 7.1 - matching unit, 7.2 - input amplifier, 7.3 inverting chip (phase inverter), 7.4 - output amplifier.

\section{Design Procedure}

\subsection{Circuit Diagram Development}

Analogue phase inverter (e.g. in Alex Jos'e Velosoa and Nascimento, 2005) which is a central part of active headphones, consists of an input and an output amplifier and meet the specifications listed in Table 1.

Table 1. Phase inverter technical requirements

\begin{tabular}{lc}
\hline Input amplifier current amplification factor, $K_{u 1}$ & -12 \\
\hline Output amplifier current amplification factor, $K_{u 2}$ & -10 \\
Operating frequency range, $\omega_{\mathrm{h}}, \omega_{\mathrm{l}}, \mathrm{Hz}$ & $50-10000$ \\
Maximum amplification current error in the operating frequency range not more than, $\%$ & 0,2 \\
Input impedance, Ohm & 0,1 \\
Input resistance accuracy, $\%$ & 1,5 \\
Amplifier output current range, $\mathrm{I}_{\mathrm{m}}, \mathrm{mA}$ & $-15 \ldots+15$ \\
Minimum allowable output impedance, Ohm & 104 \\
\hline
\end{tabular}

Input amplifier provides the necessary amplification and circuit matching with the source device . It is also used to alter the phase of the signal from the source, i.e. forms quenching wave. The output amplifier provides the necessary output characteristics of the scheme and matches it to the load.

Accumulated experience allows us to recommend an operational amplifier turned on in the inverting mode as an input amplifier. The calculation starts with the definition of component nominal values in the operational amplifier arrangement. According to Figure 3, which shows a phase inverter schematic diagram the input impedance is determined by the resistor R0, which is selected in accordance with the characteristics table (GOST 23089.17-90, 1990). Then allowable input resistance is calculated:

$$
\Delta R=\frac{R_{\mathrm{in}} \cdot \delta_{R}}{100 \%}=\frac{0.1 \cdot 1.5}{100 \%}=0.0015 \mathrm{Ohm},
$$

where $R_{\text {in }}$ is the input resistance (R0) value; $\delta_{R}\left[\right.$ delta $\left._{R}\right]$ - input resistance error.

Next, the value of the resistor R2, through which the signal is fed to the chip input is determined. Changing amplification current is available by not more than $0,003 \mathrm{Ohm}$ in predetermined frequency range.

$$
R 2 \cdot\left(\frac{1}{1+K_{\mathrm{yu}}\left(j \omega_{\mathrm{h}}\right)}-\frac{1}{1+K_{\mathrm{yu}}\left(j \omega_{1}\right)}\right)<0.003 \mathrm{Ohm},
$$

where $K_{\mathrm{yu}}$ - the gain at the cutoff frequency which is determined by a operational amplifier linear frequency response characteristic $K_{\mathrm{yu}}(50)=127 \mathrm{~dB}, K_{\mathrm{yu}}(10000)=75 \mathrm{~dB}$. 
For a small value of R0 a band-pass filter can be set in the input position. Provided that the ratio of the inverting amplifier, $\mathrm{KI}$ is minus 12, the resistor R1 and R2 nominal values are selected in accordance with the relation:

$$
K_{u 1}=-\frac{R 2}{R 1},
$$

If $\mathrm{R} 1$ and $\mathrm{R} 2$ are respectively 1 and $12 \mathrm{Ohms}, \mathrm{R} 3$ is calculated as:

$$
R 3=\frac{R 1 R 2}{R 1+R 2}=\frac{1 \cdot 12}{1+12}=0.92308 \mathrm{kOhm}=923.080 \mathrm{Ohm},
$$

The closest existing value of the resistor R3 is $920 \mathrm{Ohms}$. A lower operating frequency provides the capacitor value:

$$
C 1=\frac{1}{2 \pi R 1 f_{1}}=\frac{1}{2 \cdot 3.14 \cdot 1000 \cdot 50}=3.18 \mathrm{mkF},
$$

Then the closest existing nominal value $\mathrm{C} 1$ is $33.3 \mathrm{mkF}$.

The capacitor $\mathrm{C} 2$ nominal value is calculated in the same way:

$$
C 2=\frac{1}{2 \pi R 2 f_{\mathrm{h}}}=\frac{1}{2 \cdot 3.14 \cdot 12000 \cdot 10000}=1.33 \mathrm{nF} \approx 1.3 \mathrm{nF},
$$

Design of the output amplifier (in Figure 3) is carried out in a similar pattern. R6 and R5 equal $12 \mathrm{kOhm}$ and 120 $\mathrm{kOhm}$ respectively are chosen according to amplification current set $K_{u 2}=-10$.

Resistor R4, in this case is calculated as follows:

$$
R 4=\frac{R 5 \cdot R 6}{R 5+R 6}=10.9 \mathrm{kOhm} \approx 11 \mathrm{kOhm},
$$

So after all the calculations the device circuit diagram meets the required specifications and has the form shown in Figure 3.

Variable resistor VR1, working as a voltage divider, serves as volume control and is put before the output amplifier for a smoother adjustment. The resistor value is "default" $100 \mathrm{kOhm}$.

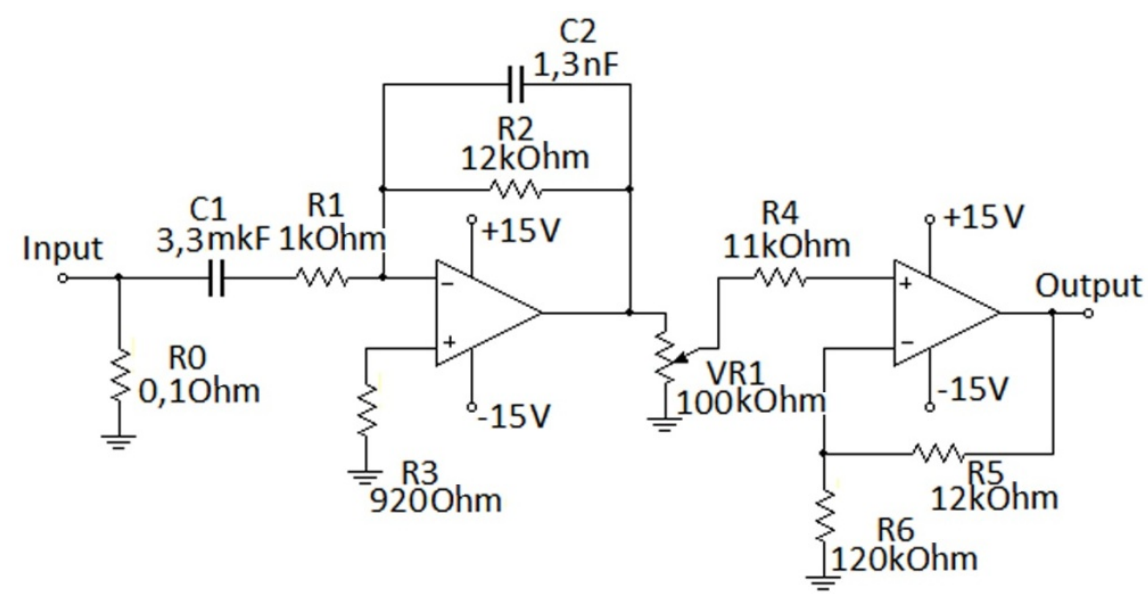

Figure 3. Phase inverter circuit diagram and values of the component elements

As analog headphones basic element base dual low noise operational amplifiers NE5532 (NE5532 Datasheet, 2009) are used. Also DC voltage converter (DCDC) ICL7660 or MAX1044 is installed. If necessary, the chip can be replaced by TL072 and TL074, after modifying the circuits arrangement.

\subsection{Designed Scheme Virtual Modeling}

For the work simulation of the designed circuit in real-time implementation of a two-channel (stereo mode) a CAD system National Instruments Multisim 11 (trial version) which has all necessary software equipment is used. For correct operation of phase inverter some changes are made in a circuit. PU mid-point, as well as a 
IC1A frequency filter were added.

The diagram shown in Figure 3, was introduced in Multisim computer-aided design system. After starting the system required parameters are:

- variable resistor is in $50 \%$ position

- $\quad$ input waveform is sinusoid

- $\quad$ input signal frequency is $1 \mathrm{kHz}$

- $\quad$ input signal amplitude is $2 \mathrm{~V}$

Tests were carried out for sound waves at 50,100, 250, 400,600, 800, 1000, 2000, 3000, 4000, 6000 and 8000 $\mathrm{Hz}$ frequency. Scheme settings remain the same, only the settings of the virtual oscilloscope scales and the signal generator parameters change. According to data received, at the given circuit parameters, the phase advance of the received signal from the signal of $50 \mathrm{~Hz}$ is equal to approximately 0.25 period, whereas $100 \mathrm{~Hz}$ signal period phase advance is equal to 0.1 . However, such data are typical only for periodic waves in case of single signal exposure, of course, the data is going to change.

At frequencies from $100 \mathrm{~Hz}$ to $2 \mathrm{kHz}$, the initial signal phase and the received signal phase do not differ. At these frequencies the most effective operation of the scheme should be provided. At a frequency of $3 \mathrm{kHz}$ and higher received signal begins to lag the phase from the source and at a frequency of $8 \mathrm{kHz}$, the phase lag is equal to approximately 0.15 periods.

Phase lag can be solved decreasing the nominal value of the capacitor C5. However, maximum efficiency should be reached not at high frequencies but at low and medium. Therefore, changes of the scheme are impractical.

\subsection{Experimental Scheme Bench Research}

The next stage of the research is to test circuits using peripheral devices in accordance with the scheme displayed in Figure 4, which was carried out as follows:

1. Test signal is fed to broadband loudspeaker. It can be either a single sound frequency or sound consisting of a set of frequencies.

2. This signal arrives at the receiving microphone 1 located on the outer side of headphones cup.

3. From the microphone the signal is sent to the sound card, and from it to the computer, where the signal is processed.

4. The signal is then supplied to loudspeaker located inside of the headset cup, and noise cancelation takes place.

5. The resultant signal gets to microphone 2 . Then it is supplied to the sound card.

6. By using special software test signal is captured for further analysis.

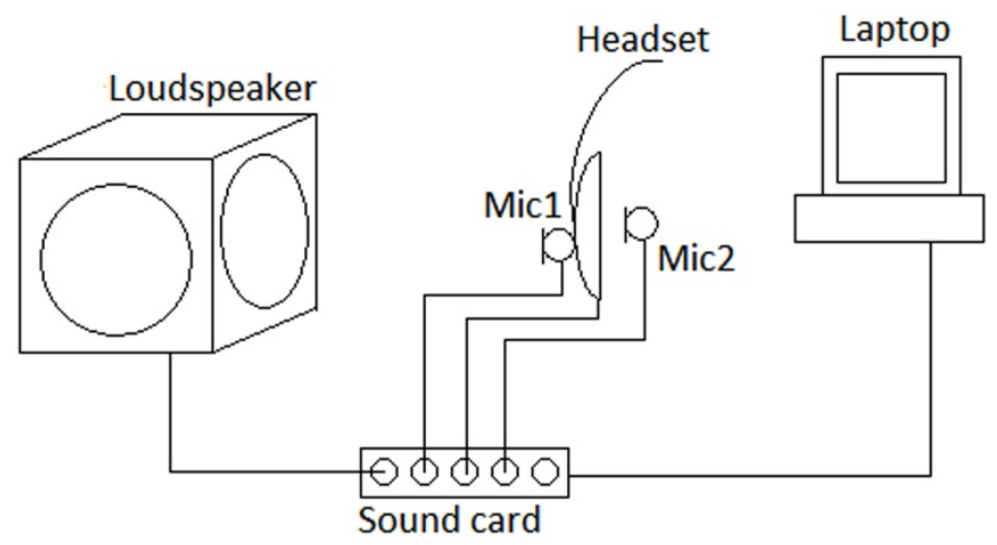

Figure 4. Test scheme

Rapid implementation of the resulting signal spectrum analysis was carried out in Adobe Audition. The results obtained in the study are presented in Table 2. This table shows the frequency response characteristic of the noise cancelation process using the designed scheme. According to the study, the acoustic efficiency of the resulting device is approximately $32 \mathrm{~dB}$, which confirms the efficiency of the designed circuit. 
Table 2. Test results

\begin{tabular}{ccc}
\hline Frequency, $\mathrm{Hz}$ & Source signal, $\mathrm{dB}$ & Resultant signal, $\mathrm{dB}$ \\
\hline 63 & 77.0 & 59.8 \\
80 & 77.0 & 62.0 \\
100 & 77.3 & 68.5 \\
125 & 79.8 & 80.0 \\
160 & 88.3 & 86.3 \\
200 & 92.5 & 85.2 \\
250 & 91.4 & 82.0 \\
315 & 89.5 & 80.6 \\
400 & 92.3 & 79.6 \\
500 & 91.4 & 80.4 \\
630 & 93.2 & 80.9 \\
800 & 92.6 & 78.6 \\
1000 & 99.0 & 79.0 \\
1250 & 100.4 & 80.8 \\
1600 & 100.4 & 82.0 \\
2000 & 102.5 & 89.1 \\
2500 & 106.1 & 93.7 \\
3150 & 111.1 & 90.4 \\
4000 & 113.4 & 88.3 \\
5000 & 105.3 & 82.2 \\
6300 & 108.1 & 74.6 \\
8000 & 100.6 & 71.8 \\
\hline
\end{tabular}

\subsection{Designing Device PCB}

The next step is to develop a circuit board of the device after assembly of the item sample and its components selection. Using SMD (surface mounted device) components can significantly reduce the size of the device. Channels on the board are divided according to a pre-designed scheme. Plug connectors for joining the volume control, as well as for the connection of microphones and loudspeakers are situated along the board edges. On the reverse side of the board supply circuit elements such as capacitors and PU mid-point resistors are located. This board showed full functionality with the noise level lower than the device model has. Self-excitation, or interference with the device is not observed even at full amplification level. Thus, the device PCB construction using surface mount components is possible.

Cups and shackle prototypes, as well as a molds prototype for headphones casting were made according to the headphones three-dimensional model. Prototypes were made of ABS plastic and painted for better visibility. All parts of active noise canceling headphones were built into the case and after the assembly of the device performance testing was carried out. Test showed it's work in normal mode with no audible noise and acoustic feedback. To test the effectiveness of the experimental sample several versions of devices with different electronic components nominal values were made.

\section{Results}

Firstly, the actual noise-canceling headphones, which are aimed at the periodic noise attenuation. Secondly, headphones designed to reduce the low frequency noise only and to amplify useful high frequency signal. Third, headphones, working in two modes: amplification and attenuation of sounds. For each of the three types of systems the main characteristics in accordance with standardized procedure (GOST R 12.4.213-99, 1990; Balagurov et al., 2012) which is adopted among international community were determined:

$-\mathrm{H}(\mathrm{L})-$ low-frequency noise reduction value, $\mathrm{dB}$.

$-\mathrm{C}(\mathrm{M})$ - midrange noise reduction value, $\mathrm{dB}$.

- $\mathrm{B}(\mathrm{H})$ - high-frequency noise reduction value, $\mathrm{dB}$.

- SNR - single noise reduction parameter, $\mathrm{dB}$.

Generalized results obtained in the research are shown in the table 3. 
Table 3. General samples performance characteristics

\begin{tabular}{lcccccccc}
\hline \multicolumn{1}{c}{ Sample \# } & \multicolumn{3}{c}{ Periodic noise reduction characteristics, dB } & \multicolumn{4}{c}{ Impulse noise reduction characteristics, } \\
\hline & H(L) & C(M) & B(H) & SNR & H(L) & C(M) & B(H) & SNR \\
Sample \# 1 & 13 & 20 & 33 & 32 & 11 & 17 & 26 & 25 \\
Sample \# 2 & 11 & 17 & 29 & 28 & 9 & 14 & 25 & 24 \\
Sample \# 3 & 12 & 20 & 33 & 32 & 11 & 17 & 26 & 25 \\
$\begin{array}{l}\text { Peltor SportTac } \\
\text { headphones }\end{array}$ & 15 & 21 & 34 & 33 & 13 & 19 & 27 & 26 \\
\hline
\end{tabular}

The Table 3 data analysis shows that:

1. Sample \# 1 has characteristics which exceed calculated ones for several decibels. It fully copes with the task set.

2. Despite slightly worse performance sample \# 2 can allocate useful signal from the overall signal. This is an advantage because the majority of teamwork production problems can be solved.

3. Sample \# 3 has characteristics similar to the sample \#1. However, this device has the possibility to amplify the signal, and hence its application is not restricted only in manufacturing.

All three samples show high performance. Experimental samples characteristics comparison showed no significant differences in the effectiveness.

Figure 5 shows the comparison chart of experimental samples with Peltor Sport Tac Hunting headphones (Technical specification on Peltor ${ }^{\mathrm{TM}}$, 2009) under the impulse noise exposure. These headphones are equipped with a digital noise reduction system that gives them an advantage over analogue headphones.

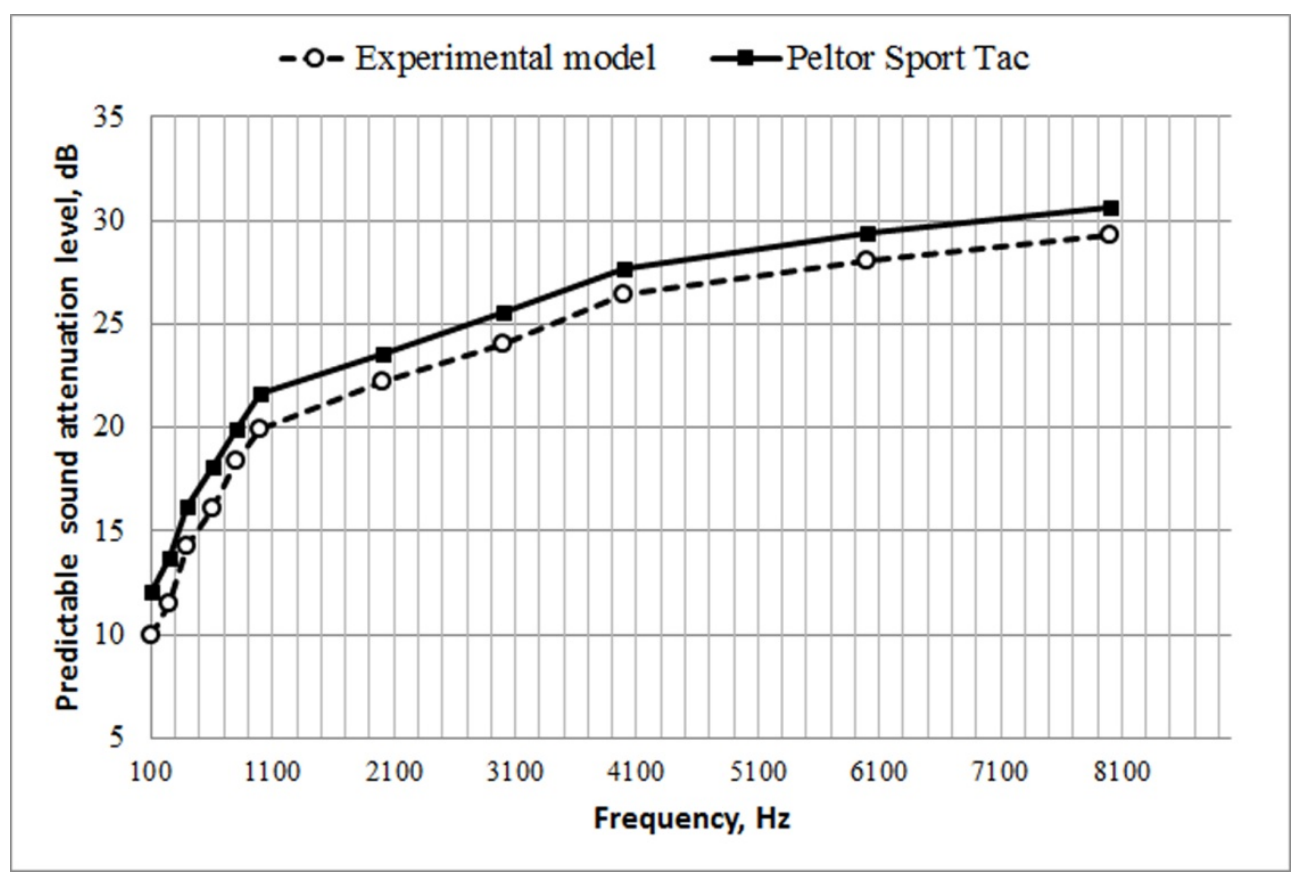

Figure 5. Characteristic comparison of the experimental sample and Peltor SportTac headphones under the impulse noise exposure

The diagram shows that the performance of the experimental samples are close to those of Peltor headphones. Thus, the experimental model has shown its competitive ability and can be used for implementation in production.

\section{Discussion}

An experimental sample of active noise canceling headphones was designed and built during the research. 
Distinctive differences from their known analogs lie in the fact that they consist of headphones cups with loudspeakers and microphones with the additional processing unit, which consists of series-connected matching unit, the input amplifier, phase inverter and the output amplifier. The output of the input amplifier is also connected to an input of the output amplifier connected to loudspeakers. Forementioned matching unit is arranged to set the operating mode of active headphones depending on the function to be performed by active headphones: noise exposure reduction or use as an auxiliary means of hearing; by supplying a signal respectively either to the inverting chip, or directly to the output amplifier.

The proposed method of active headphones signal processing comprising signal transmission from microphones to loudspeakers, is that the signal from the microphones is fed to a processing unit in which the signal is aligned, amplified, and then inverted with following amplification, or just amplified without any inversion. After that the processed signal is supplied to broadband loudspeakers. With the signal alignment the headphones mode selection depending on the function that should active headphones perform is provided: reduction of noise exposure or use as an auxiliary means of hearing; by supplying the signal to the inverting chip or directly to the output amplifier, respectively.

To improve the efficiency of noise protection it is expected to build in both headphones cups additional microphones to allocate speech from the overall noise. One microphone receives a signal representing a speech mixed with noise while the other microphone, axis of which is perpendicular to the axis of the main microphone receives the background noise. Background noise is inverted and then mixed with the main signal. Thus, attenuation of the background noise is obtained without any loss of the speech signal.

In this case there is an increase in the total number of microphones from two to six. An additional positive effect of the active headphones and signal processing method they provide is the possibility of their use for amplification of the speech signal, including as an aid for hearing impaired people.

Another positive effect is the possibility of using standard headphones available in everyday life. Either digital or analog signal processing technology can be implemented in active headphones. The headphones cups geometric shape can be arbitrary.

\section{Conclusion}

Primarily the emphasis was placed on reducing sample cost without efficiency loss. This was achieved through the use of analogue components in the device. Also, to improve the efficiency and ergonomics of the developed means of hearing protection the work on the designing of the of active noise canceling headphones body shape was carried out. The result of the work is the industrial implementation of the active noise canceling headphones sample. After a series of studies a high efficiency of the device has been revealed. Most of the characteristics exceed the criteria that had to be achieved according to target specifications.

\section{Acknowledgments}

This work was supported by the Russian Foundation for Basic Research (grant 14-07-31100\14) and Foundation for Assistance to Small Innovative Enterprises in Science and Technology (project on competition START 12 H2, state contract number 10270p/18092).

\section{References}

Akhtar, M.T., Abe, M., \& Kawamata, M. (2004). Modified-filtered-x LMS algorithm based active noise control systems with improved online secondary-path modeling. Circuits and Systems. MWSCAS '04. The 2004 47th Midwest Symposium, 13-16. http://dx.doi.org/10.1109/MWSCAS.2004.1353885.

Alex Jos'e Velosoa, A. J., \& Nascimento, V. H. (2005). Headphone with Active Noise Control using Analog Adaptive filter. Proceedings of the Congress and Exposition on Noise Control Engineering: Environmental Noise Control. Retrieved from http://www.lps.usp.br/vitor/artigos/internoise05.pdf

Arrangement in acoustic headsets. Patent US № 6965681 B2. Retrieved from http://www.google.com/patents/US6965681

Balagurov, A. V., \& Tyurin, A. P. (2011). The actual trends of the noise safety. In A.I. Sidorov (Ed.), Life Safety in the eyes of Youth: Proceedings of the II ${ }^{\text {nd }}$ All-Russian Student Conference (with International participation) (pp. 8-9). Chelyabinsk, Russia: "South Ural State University" (National Research University).

Balagurov, A. V., Tyurin, A. P., Korepanova, E. P., \& Pigalev, S. A. (2012). Estimation of the noise attenuation efficiency of personal hearing protection means. In A.I. Sidorov (Ed.), Life Safety in the third millennium: Proceedings of the $V^{\text {th }}$ International Scientific and Applied Conference (pp. 228-232). Chelyabinsk, Russia: 
"South Ural State University" (National Research University).

Chashechniy naushnik s microfonnim ustroistvom. Patent RU № 2007144203 A. Retrieved from http://www1.fips.ru/Archive/PAT/2009FULL/2009.06.10/DOC/RUNWA/000/002/007/144/203/document.p df

Chong Lo, A. H., \& McPherson, B. (2013). Hearing screening for school children: Utility of noise-cancelling headphones. BMC Ear, Nose and Throat Disorders, 13(6). http://dx.doi.org/10.1186/1472-6815-13-6

Elamin, F, Gu, F., \& Ball, A., (2010). Diesel Engine Injector Faults Detection Using Acoustic Emissions Technique. Modern Applied Science, 4(9). http://dx.doi.org/10.5539/mas.v4n9p3

Gaikwad, P., Jain, M., Yevle, P., \& Bhandari, S. U. (2013). Active Noise Control Using Field Programmable Gate Arrays. International Journal of Advanced Research in Electrical, Electronics and Instrumentation Engineering, 2(2), 793-799. $\quad$ Retrieved from www.ijareeie.com/upload/february/7-Active\%20Noise\%20Control.pdf

Gan, W. S., \& Kuo, S. N. (2003). Integrated Active Noise Control Communication Headsets. Proceedings IEEE International Symposium on Circuits and Systems, 353-356. http://dx.doi.org/10.1109/ISCAS.2003.1205846

GOST 23089.17-90. (1990). Integrated microcircuits. Methods of measuring input and output resistances of operational amplifiers.

GOST R 12.4.213-99. (1990). Occupational safety standards system. Hearing protectors. Simplified method for the measurement of insertion loss off ear-muff type protectors for quality inspection purposes.

Instruction Manual: Hearing-Protector Test Fixture Type 45CA. Retrieved August, 15, 2014, from http://www.gras.dk/media/docs/files/items/m/a/man_45CA.pdf

Molesworth, Brett R. C., Burgess, Marion, K., \& Daniel, (2013). The use of noise cancelling headphones to improve concurrent task performance in a noisy environment. Applied Acoustics (Elsevier), 74(1), 110-115. http://dx.doi.org/10.10 10.1016/j.apacoust.2012.06.015

NE5532 Datasheet: Dual low-noise operational amplifires. (2009). Retrieved from http://www.ti.com/lit/ds/symlink/ne5532.pdf

Pawelczyk, M. (2001). Analogue active noise control. Applied Acoustics, 63(11), 1193-1213. http://dx.doi.org/10.1016/S0003-682X(02)00027-0

Ryckebusch, J. (1997). Build these noise-cancelling headphones. Electronics Now, 68(9), 31. Retrieved from $\mathrm{http} / / /$ connection.ebscohost.com/c/articles/9710065902/build-these-noise-cancelling-headphones

Schumacher, T., Kruger, H., Jeub, M., Vary, P., \& Beaugeant, C. (2011). Active noise control in headsets: A new approach for broadband feedback ANC. Proceedings of the IEEE International Conference on Acoustics, Speech and Signal Processing (ICASSP) (pp. 417-420). Prague, Czech Republic.

Technical specification on Peltor ${ }^{\mathrm{TM}} 3 \mathrm{M}$ Occupational Health \& Environmental Safety Division. Hunting and Sport Shooting. Retrieved Jule, 15, 2009, from http://peltorcomms.3m.com/Admin/files/20100509202809.pdf

Thom, J., Peters, Ch., McIntyre, E., Winters, M., Teschke, K., \& Davies, H. (2005). Active noise control communication headsets for the entertainment industry. Prepared for Safety and Health in Arts Production and Entertainment (SHAPE). Retrieved July 15, 2014, from http:// circle.ubc.ca/bitstream/handle/2429/815/ANCHeadsetsFinalRevised.pdf?sequence=1

\section{Copyrights}

Copyright for this article is retained by the author(s), with first publication rights granted to the journal.

This is an open-access article distributed under the terms and conditions of the Creative Commons Attribution license (http://creativecommons.org/licenses/by/3.0/). 